\title{
Os novos professores catedráticos
}




\section{Dr. Mário Masagão}

Professor cated rático de Direito Administrativo e Ciência da Administração.

Filho de Thiago Masagão e D. Cândida do Amaral Carvalho Masagão, nasceu em São Carlos, dêste Estado, a 9 de outubro de 1899.

Bacharelou-se em Ciências Jurídicas e Sociais, pela Faculdade de Direito de São Paulo, em 1919, passando a exercer a advocacia.

Em Setembro de 1927, inscreveu-se em concurso para docência livre de Direito Administrativo e Ciência da Administração, na mesma Faculdade. Realizado em Outubro de 1928 aquele concurso, foi unanimemente aprovado, com grau 10, e nomeado docente livre por portaria de 14 de Novembro, assumindo o exercício do cargo a 16 do mesmo mês.

Foi logo depois encarregado da regência da cadeira, em substituição ao Professor Catedrático, Dr. Manoel Pedro Villaboim, substituição que exerceu durante cinco anos consecutivos.

Em 1931 regeu também a cadeira de Economia Política e Ciências das Finanças, em substituição, no $2 .^{\circ}$ ano do curso, do respectivo Professor Catedrático, Dr. J. J. Cardoso de Mello Neto.

Em 1930, fez parte da Comissão Examinadora, em concurso para docência livre de Direito Público e Constitucional.

Por decreto de 12 de Dezembro de 1930, foi nomeado Ministro do Tribunal de Justiça do Estado, com assento na Segunda Câmara. No ano seguinte passou a ter assento na Quarta Câmara do mesmo Tribunal. 
Em 1933 inscreveu-se em concurso para provimento da vaga de professor catedrático de Direito Administrativo, ocorrida com a aposentadoria do Dr. Manoel Pedro Villaboim. Unanimemente aprovado, de novo com grau 10 , foi nomeado professor catedrático daquela disciplina, por decreto de 25 de Setembro de 1933.

De 22 de agosto a 15 de dezembro de 1933, exerceu o cargo de Secretário da Justiça e da Segurança Pública do Estado, no início do govêrno do Interventor Dr. Armando de Salles Oliveira.

A 4 de outubro de 1933, em sessão solene da Congregação, tomou posse do cargo de Professor Catedrático de Direito Administrativo.

Em eloquente improviso, o Exm ${ }^{\circ}$. Sr. Dr. Diretor da Faculdade, Prof essor Alcantara Machado, saudou, em seu nome e no da Congregação, o novo professor, fazendo-lhe o elogio.

Respondeu, também improvisadamente, o Dr. Mário Masagão, com palavras de agradecimento, e acentuando bem compreender a extensão da responsabilidade que the pesava sôbre os ombros, ao assumir a cátedra que fôra ilustrada por professores como Manoel Pedro Villaboim e Cardoso de Mello Neto. No desempenho da tarefa empenharia toda a dedicação que em suas fôrças coubesse, e não desfitaria os olhos do diuturno exemplo que constituia a atuação dos seus eminentes Mestres da Congregação da Faculdade.

Os discursos não foram taquigrafados.

\section{OBRAS PUBLICADAS:}

O Projeto do Código do Processo. - S. Paulo, Tipografia Indiana, 1925.

Conceito do Direito Administrativo. - S. Paulo, Escolas Profissionais Salesianas, 1926.

Em face da Constituição Federal, não existe, no Brasil, o Conten-i cioso Administrativo. (Dissertação para concurso). São Paulo, Secção de Obras do Estado de S. Paulo, 1927.

Natureza Juridica da concessão de serviço público. (Dissertação para concurso). São Paulo, Saraiva \& Cia., 1933. 


\section{Dr. Gabriel José Rodrigues de Rezende Filho}

Professor catedrático de Direito Judiciario Civil.

Nasceu na Capital de S. Paulo, aos 23 de junho de 1893.

Filho do dr. Gabriel José Rodrigues de Rezende, professor catedrático da Faculdade de Direito de S. Paulo, já falecido, e de d. Maria Constança Benevides de Rezende.

Bacharel em ciências e letras pelo Ginásio de S. Bento, desta Capital, em 1908.

Bacharel em ciências juridicas e sociais pela Faculdade de Direito de S. Paulo, em 1913.

Obteve distinção em todo o curso jurídico, sendo-lhe conferido o premio "Duarte Azevedo"

Em 1917, prestou concurso para o preenchimento da vaga de professor substituto de Teoria e Prática de Processo Civil e Comercial, colocando-se em segundo lugar.

Em 1919, por voto unanime da Congregação, obteve o título de livre-docente da referida disciplina.

Em 1925, foi-lhe conferido o gráu de doutor em direito.

Em 1926, por motivo do falecimento do professor dr. Estevão de Almeida, assumiu a regência da cadeira de Teoria e Prática do Processo Civil e Comercial.

Substituiu tambem, em 1927, 1928 e 1929, na regência da mesma matéria, o professor dr. Francisco Morato.

Substituto, ainda, em 1931, e parte de 1932.

Representou a classe dos livre-docentes da Faculdade no Concelho Nacional do Ensino, no Rio de Janeiro, ininterruptamente, de 1927 a 1930.

Em 1926, 1928 e $1931 \mathrm{fez}$ parte de bancas examinadoras em vários concursos para livre-docentes, tendo ainda exami- 
nado dois candidatos, que pretendiam a revalidação de seus diplomas, outorgados por Faculdades estrangeiras.

Em Outubro de 1933, prestou concurso para o cargo de professor catedrático de Direito Judiciario Civil, nesta Faculdade, sendo classificado, unanimemente, em 1. ${ }^{\circ}$ lugar.

Nomeado por decreto do Govêrno Provisório em 3 de janeiro de 1934, tomou posse de seu cargo em 23 do mesmo mês, proferindo o discurso abaixo transcrito.

"Exmo. sr. Diretor da Faculdade de Direito:

"Bem sei quão traidoras são as emoções e como o nosso fragil coração, numa ocasião destas, quasi sempre emudece.

"Trouxe, por isso, por escrito, as palavras singelas que me curnpre dizer neste momento.

"As bondosas e cativantes expressôes de V. Excia. - digno ornamento desta Egrégia Congregação - penetraram fundo em minh'alma.

"Aproveitando um pensamento de Rúi Barbosa, posso afirmar que a oração do meu prezado mestre e amigo me daria sobejo motivo de ufania, considerando-me o homem mais desvanecido dêste mundo, se a conciência - vigia fiel da justiça no intimo de meu sếr - acostumada a conhecer-se, em não estivesse pondo ante os olhos, com o seu espêlho cristalino, a imagem real da minha desvalia.

"Agradeço de coração a V. Excia. e á douta Congregação da Faculdade a acolhida que me fazem.

"Aqui comecei e concluí os meus estudos, em meio dos encantos, dos rumores e dos anseios, tão proprios da mocidade despreocupada, sob estas arcádas que guardam perenemente o éco de tantas glórias passadas, e, mal saido para a vida prática, já alimentava o ideal de um dia aqui ingressar como professor, afim de continuar a tradição de minha gente, honrando o nome de meus Avós e de meu Pai, que foram grandes mestres de direito.

"Realiza-se hoje, afinal, a justa ambição, o grande sonho de minha vida, tão ardentemente acalentado.

"Entro definitivamente para esta gloriosa Eseóla, cheio de emoções a de receios, mas animado pela vontade de tudo fazer por ela.

"Não sei descrever, nem há palavras que possam bem traduzir a formidavel atração que sempre exerceu em meu espírito esta Faculdade.

"Talvez a vóz do sangue para ela me chamasse, vóz de meus antepassados, a insuflar em mim o mesmo zêlo que tiveram por êste 
Templo do Direito; talvez, o esplendor e a fulgurância de suas tradições nobilissimas.

"Sinto, porisso mesmo, a enorme responsabilidade que assumo, mas por bem recompensado darei o meu esforço se conseguir, sem brilho embóra, mas honestamente, cumprir o meu dever, na medida das forças que Deus me concedeu.

"Entrando para o vosso convívio, mestres e amigos, sentandome ao vosso lado, prometo a minha decidida e leal colaboração para a maior eficiência das coisas do ensino e para o maior lustre do nome aureolado da nossa Faculdade.

"Como livre-docente, palmilhando cêdo a estrada do magistério, áspera, cheia de óbices, amena, no entanto, pelas satisfações morais que compórta, dei mostras de ter procurado, esforçadamente, cumprir as minhas obrigações, substituindo com desvêlo, mestres notaveis no ensino da dificil disciplina, que é o Processo Civil.

“A experiência proveitosa de alguns anos de cátedra convenceume de que é preciso seguir novas diretrizes, orientando o ensino juridico para uma finalidade mais racional e menos acanhada.

"Tenho para mim que bem longe já vai, felizmente, a época do absolutismo do magister dixit, das aulas massudas e enfadonhas de pura exibição oratória.

"A missão do professor de direito deve ser, antes de mais nada, a de um guia, a de um orientador que, entremostrando aos alunos as sérias dificuldades da matéria, procure, porisso mesmo, ao expôr os princípios teóricos, imprescendiveis, dar aulas práticas, tornando menos fastidioso, mai s agradavel e proveitoso o trabalho comum.

“Com razão dizia o meu sábio e saudoso mestre João Mendes, que o estudo do direito compreende, primeiramente, o estudo de sua natureza, de seus princípios, de seus preceitos, de suas leis.

"Mas, o direito, sem embargo de constituir uma ciência especulativa quanto ao modo de saber, é eminentemente prática quanto ao fim, porque o direito é para ser aplicado aos fátos da vida.

"O intelecto simplesmente especulativo, acrescentava o mestre, considera o ponto de vista da verdade; o intelecto prático não abandona o ponto de vista da verdade, mas estende-se á operabilidade e, depois, á operação.

"Na ordem especulativa, contemplamos a verdade dos principios e a retidão das leis, como, na ordem prática, contemplamos a realidade dos fátos e a aplicabilidade das leis.

"Não há, assim, nem póde haver, incompatibilidade entre a teoria e a prática.

"Ainda recentemente, na introdução de seu programa de Direito Judiciário Civil, o eminente professor Candido de Oliveira Filho afirma, baseado na lição de Savigny, que - "é falsa a opinião que 
considera a teoria e a prática do direito como coisas diversas e mesmo opostas.

"Sem dúvida, o teórico e o prático tem cada um as suas funções.

"A aplicação, que fazem de seus conhecimentos, é diferente; mas, seguindo uma mesma ordem de idéias, seus estudos devem ser os mesmos e ninguem exercerá dignamente a teoria ou a prática si não tiver conciência de sua identidade.

"Sendo o mal capital, de que padece o direito vigente, o divórcio, cada dia mais pronunciado, da teoria e da prática, o remédio está no restabelecimento de sua unidade natural"

“Cumprindo tão necessário quão agradavel objetivo, não descurei, nas minhas aulas, de ministrar aos estudantes, quanto possivel, em meio de cursos nem sempre completos ou regulares, o conhecimento teórico-prático do Processo Givil.

"O ensino exclusivamente prático, pelo case-system, sistema de laboratório, por alguns exageradamente encomiado, parece-me bastante empírico, simplista, mesquinho mesmo, bem fóra das tradições desta Faculdade e quiçá das tendencias insopitaveis da nossa raça.

"Não basta, com efeito, ensinar a teoria pela análise dos casos práticos, apreciar as questões judiciarias concretas para delas inferir os princípios e as regras jurídicas.

"Mais alguma coisa é preciso: as Faculdades de Direito não devem ser apenas institutos de altos estudos, mas não pódem constituir tambem méros laboratórios, méras escolas profissionais.

"Requer-se o meio termo, adotando-se o método mixto, analítico-sintético, conjugando-se adequadamente o ensina teórico-especulativo dos fundamentos do direito com a sua aplicação aos fátos, com modo de formação e realização das relações juridicas, quer no fôro extra-judicial, quer no fôro judicial.

"Fato é que o ensino que não estimula, que não incentiva, que não desenvolve a faculdade de iniciativa dos alunos e nem favorece a capacidade de cada um, no sentido da crítica pessoal, da observação, do raciocínio e da generalização, é evidentemente um ensino deficiente e vazio.

"Acabe-se de vez com o método exclusivo das lições-monólogos; tenha-se como incontestavel verdade que não é possivel limitar a função pedagógica da escóla á ação unilateral do professor; apéle-se, com freqüência, para as argüições dos alunos, para os exercícios, consonantes aos assuntos explanados, afim de que se possa imprimir ao ensino a concretização necessária á aproximação entre os princípios e os fatos, á valorização da doutrina exposta nas preleções e á formação do hábito de encarar o direito nas suas relações com a vida social — e com tais estímulos conseguir-se-á, 
por certo, o aproveitamento geral pelo conhecimento reciproco e pela cooperação mais intima entre mestres e alunos no estudo e desenvolvimento dos programas.

Essa a orientação que me propús, ao reger interinamente a cadeira de Processo Civil, orientação que confio aperfeiçoar paulatinamente, doravante, com programa próprio e com a devida autonomia.

\section{Sr. Diretor.}

"Animado de tais propósitos, assumo hoje, desvanecido, o posto de professor catedrático de Direito Judiciário Civil.

"Na alegria inolvidavel dêste dia, só me punge a tristeza de não vêr sentado aqu ao lado dos mestres e amigos, a figura de meu Pai, que, pela sua superior educação, pelo seu trato ameno e generoso e pelas suas -elevadas qualidades morais e intelectuais, permitam-me dizê-lo, nesta evocação de ternura filial, foi um dos expoentes desta Faculdade.

"Talvez êle sorria lá de cima -- com aquele sorriso tão bom. tão seu - alegrando-se por vêr que o seu filho se abalança corajósamente a sentar-se nesta Congregação ilustre, e eu sinto, em verdade, que sôbre mim paira o seu espírito, que jamais morreu para a minha saudade, saudade de todos os dias e de todas as horas, saudade eterna, saudade enraigada bem no fundo de minh'alma, como a impelir-me a seguir sempre o seu nobilitante exemplo, perpetuando da melhor maneira o seu nome honrado.

"Ufanando-me de pertencer agóra a esta Casa, que não é apenas um relicário de glórias fenecidas, mas um centro de energias sempre renovadas, onde se cultúa serenamente o direito e onde se evangeliza a verdade - prometo, solenemente, envidar todos os meus esforços, cooperando convosco, mestres e amigos, na obra comum de defesa do patrimonio moral e de engrandecimento da nossa querida Faculdade!”

Escreveu as seguintes dissertações:

Para que se dê a competencia do fôro do cunirito é essencial que as partes tenham feito renúncia expressa do fôro do domicilio? Por que principios se rege a apelacão de terceiro:

Modificações objetivas e subjetivas da ação. 


\section{Dr. Jorge Americano}

Professor catedrático de Direito Civil.

Natural de São Paulo, onde nasceu, á rua Episcopal n." 4, em 25 de Agosto de 1891. Filho da C.l Luiz Americano e de D. Amelia Cardoso Americano. Casou-se em 11 de Setembro de 1917 com D. Maria Raphaela de Paula Souza Americano, filha do Dr. Calisto de Paula Souza e D. Elfrida Pacheco de Paula Souza.

Fez estudos primários na Escola Modelo Caetano de Campos, onde se matriculou em 1898, até 1902, e estudos secundários no Ginásio de São Paulo, onde se matriculou em 1903 , cursando-o até 1907 .

Matriculou-se em 1908 na Faculdade de Direito de São Paulo, formando-se em 1912.

De 1909 a 1915 foi escriturário do Tesouro do Estado de São Paulo, tendo exercido em comissão de 1913 a 1914 o cargo de oficial de gabinete do Secretário da Fazenda, e em 1913 interinamente o de sub-procurador fiscal da Fazenda.

Em 1915 foi nomeado promotor Público de Bebedouro, cargo que exerceu até 1918, permutando então com o de Atibaia, de onde se exonerou, transferindo residência para São Paulo, até 1921.

Advogado em Santos, de 1921 a 1928, fez concurso em 1927 para a Faculdade de Direito, tirando a livre-docência. Foi eleito deputado estadual pelo $10 .^{\circ}$ distrito, em 1927, sendo-lhe renovado o mandato em 1928. De 1927 a $1928 \mathrm{fez}$ parte da Comissão organizadora do projeto do Código do Processo do Estado de São Paulo. Renunciou ao mandato e se exonerou da Comissão por ter sido nomeado Procura- 
dor Geral do Distrito Federal, cargo que exerceu de 1928 a 24 de Outubro de 1930, abandonando-o voluntáriamente nessa época.

Nesse ano voltou a São Paulo, onde passou a residir, com escritório de advocacia, exercendo o magistério no Ginasio de São Bento, na Escola de Comércio Alvares Penteado e, como livre docente, na Faculdade de Direito de São Paulo.

Foi ferido na explosão do Quartel General da Fôrça Publica, logo no início da guerra Constitucionalista em 1932. A-pesar-disso, logo depois organizou, em colaboração com os professores da Escola Politécnica e do Instituto de Higiene, o curso de aperfeiçoamento de instrução para oficiais voluntários combatentes, preparando tres turmas até o fim da luta.

Terminada a revolução e iniciada em 1933 a campanha eleitoral, foi in dicado deputado á Assembléia Nacional Constituinte, pela chapa "Por São Paulo Unido", das correntes constitucionalistas coligadas.

Durante o periodo entre a eleição, em 3 de Maio, e a instalação da Assembléia, em Novembro, fez concurso á cadeira de Direito Civil da Faculdade, sendo classificado em primeiro lugar.

Eleito e empossado na Assembléia Nacional Constituinte, renunciou o mandato logo a seguir.

Tornando a São Paulo em Dezembro de 1933, tomou posse do cargo de Professor Catedrático de Direito Civil em 21 de Fevereiro de 1934, para que foi nomeado por concurso prestado no ano anterior, proferindo o discurso adiante transcriro.

"A Grande Guerra propôs ao mundo as perguntas a que êste segundo quarto de século procura responder:

"Repousa a civilização anterior a 1914 em bases legítimas, que convenha consolidar? Ou, ao contrário, o grande abalo impôs reconstruir todo o edificio, desde as bases?

"Terá sido a guerra a causadora das fendas que se lhe notam? Ou apenas terá revelado os vícios preexistentes, da organisação social moderna? 
"Quando a sociedade chega a formular semelhantes perguntas, exige que lhas respondam, ou ela própria se dispõe a fazê-lo. E então age sob a pressão de todo o mal-estar acumulado, mas com a inconciência de quem desconhece o perigoso laboratório em que atúa.

Tambem o professor estuda hoje sob a pressão dos fatos sociais. Cabendo-lhe a responsabilidade de preparar o meio dirigente, é forçado, a cada passo, a refazer o exame das suas noções básicas.

"Pertenço a uma geração que, na economia, na política, no direito, ainda fez o estudo direto do meio anterior a 1914. Presenciou os abalos e foi testemunha das criticas, antes que o seu espirito sofresse o processo de cristalização que faz enxergar em cada preconceito uma verdade definitiva. Por outro lado, tendo vivido uma época que proporcionou consideravel soma de bem, pôde ver que nem tudo nela era erro.

"Tendo aberto os olhos sob certa luz, conserva-lhe a impressão. Mas não cegou para a luz nova, que revela novas fórmas. Essa geração, ainda ligada ao passado, não é irremissivelmente apegada a êle. E' livre de espirito para perscrutar o futuro, para o qual the incumbe salvar o patrimônio moral que, do passado, mereça guardar-se.

"Conhecedores do patrimônio antigo, e aptos a receber o que é novo, teremos feito muito se, daquele, conservarmos o que tem de bom, sem repelir dêste o que tèm de generoso.

"Vou ter para alunos de Direito Civil os moços da época nova, sob cuja luz, antes de receberem do professor as noções clássicas, já conceituaram socialmente a familia, a propriedade, as obrigações, a sucessão por herança.

"Se, em tempos calmos, o ensino é pesado, mais o é agora, quando qualquer pequena incompreensão provoca o embate das mentalidades. Muito mais nesta Casa, sôbre a qual São Paulo tem o olhar carinhoso e atento, na ansiedade de que seus filhos saibam prosseguir na esteira luminosa de mais de um século, servindo-o com amor, probidade e cultura.

“Á Congregação da Faculdade de Direito de São Paulo, a que desde agora tenho a honra de pertencer, direi que considero a investidura na cátedra o princípio de uma carreira que só se corôa pelos frutos que produz - - pelo valor dos novos discipulos - feitos advogados, honestos guardas do espirito da Escola; legisladores, intérpretes da sua mentalidade clara; politicos, fortes defensores de ideais; magistrados, concientes distribuidores de justiça; professores, insatisfeitos de saber, verdadeiros cultores do Direito, portadores da luz mais alta." 


\section{OBRAS PUBLIGADAS:}

Da ação rescisória dos julgados no Direito Brasileiro (1922).

Da ação pauliana (1923).

A lição dos fatos (1924).

Do ato ilicito nos acidentes do trabalho (1925).

Processo civil e comercial no Direito Brasileiro (1925).

Da ação rescisoria (2." ed. 1925).

Dos direitos que se exteriorizam pela posse (1926).

Da ação pauliana (2." ed. 1932).

Aplicações do Direito (1930).

Ensaio sôbre o enriquecimento sem causa (1933).

Tem mais, no prélo, uma obra, em quatro volumes, de comentários ao Codigo do Processo Civil e Comercial do Estado de São Paulo. 


\section{Dr. Ernesto de Moraes Leme}

Professor Catedrático de Direito Comercial.

Nasceu em Bragança, neste Estado, a 30 de dezembro de 1896. Filho de Candido de Moraes Leme e de d. Maria da Conceição Leme.

Fez seus estudos preliminares no Segundo Grupo Escolar do Braz e no Grupo Escolar do Pary, nesta Capital, concluindo-os no Grupo Escolar "Dr. Jorge Tibiriçá”, de Bragança, onde se diplomou a 30 de novembro de 1909.

Em princípios de 1911, após o competente exame de admissão, matriculou-se na Escola Normal de Pirassununga, de onde se transferiu, terminado o terceiro ano, para a Escola Normal de Campinas, aí recebendo o diploma que o habilitou para o magistério primário, a 15 de dezembro de 1914.

Nomeado substituto efetivo do Grupo Escolar de Bebedouro, por ato de 16 de janeiro de 1915, matriculou-se, meses após, na Faculdade de Direito de São Paulo, recebendo o grau de bacharel em ciências juridicas e socais a 5 de dezembro de 1929. Sorteado para o serviço militar, foi incorporado ao estado efetivo do $52 .^{\circ}$ Batalhão de Caçadores, no Rio de Janeiro, a 18 de março de 1918. Obteve transferência, em 10 de abril, para a $6 .^{a}$ Região Militar, com séde em São Paulo, onde serviu no 43. ${ }^{\circ}$ Batalhão de Caçadores, recebendo sua caderneta de reservista a 17 de fevereiro de 1919. Durante êsse ano foi, por alguns meses, redator da "Gazeta de Notícias", do Rio de Janeiro.

Obtido seu diploma de bacharel, abriu escritório de advocacia, em janeiro de 1920, na comarca de Catanduva, 
recem-instalada. Daí se transferiu, em começos de 1921, para Rio Preto, de onde se mudou, definitivamente, para esta Capital, em junho de 1922.

Ingressando, em fins de 1923, no Instituto da Ordem dos Advogados de São Paulo, foi eleito, tempos depois, membro do Concelho, cargo que deixou, em 1927, para exercer o de secretário da mesma instituição, na presidência Antonio Mercado. Findo o seu mandato, em 1930, foi novamente eleito membro do Concelho do Instituto, cargo que ainda exerce.

Criada, por decreto do Govêrno Federal, a Ordem dos Advogados do Brasil, foi o dr. Ernesto Leme um dos onze primeiros diretores da secção de São Paulo, da qual foi o primeiro secretário. Eleita a diretoria definitiva, em janeiro de 1933, foi novamente investido das funções em que ainda se encontra, de membro do Concelho da Ordem.

Em 15 de março de 1926, foi nomeado, pelo Secretário da Justiça e da Segurança Publica, sr. Bento Bueno, examinador no concurso de juiz substituto do $50^{\circ}$ distrito judicial; a 8 de fevereiro de 1927, por decreto do presidente do Estado, sr. Carlos de Campos, foi nomeado examinador no concurso para juizes preparadores das comarcas de Araraquara, Barretos, Botucatú, Assis, Jaboticabal, Piracicaba, Rio Preto, São Carlos, São João da Bôa Vista e Itapetininga; a 8 de novembro de 1930, nomeou-o o secretario da Justiça e da Segurança Publica e presidente provisório do Estado de São Paulo, sr. Plinio Barreto, para examinador no concurso de juiz substituto do $18 .^{\circ}$ distrito judicial.

Nomeado, a 17 de novembro de 1930, por ato do sr. Ministro de Estado dos Negócios da Agricultura, Indústria e Comercio, fiscal dos estabelecimentos de ensino técnico comercial, regidos pelo dec. n. 17.329, de 28 de maio de 1926 , dessas funções se exonerou, logo após. Cometeu-lhe, então, o govêrno do Estado, o cargo de promotor de residuos da comarca da Capital, para o qual foi nomeado, interinamente, por ato de 19 de janeiro de 1931, sendo efetivado por decreto de 15 de julho do mesmo ano. Por decreto de 28 de maio 
de 1931, foi tambem nomeado professor catedrático da 10. cadeira, (Direito Público e Constitucional, da Faculdade de Ciencias Economicas e Sociais.

Submeteu-se, em agosto de 1933, ao concurso para provimento da cadeira de Direito Comercial, da Faculdade de Direito de São Paulo, na vaga aberta com o falecimento do professor Octavio Mendes. Classificado em primeiro lugar, foi nomeado a 19 de fevereiro do corrente ano, por decreto do chefe do Govêrno Provisório, sendo empossado no cargo de professor catedrático e recebendo o gráu de doutor em direito, a 17 de marco p. p. Nessa solenidade proferiu o discurso que vai adiante transcrito.

\footnotetext{
"Exmo. Sr. Diretor,

Ilustrados membros da Congregação,

Minhas senhoras,

Meus senhores:
}

"Eu poderia dizer com Afranio Peixoto, embora tomando a sua frase em outro sentido, que a minha primeira ambição conciente foi esta: ser acadêmico.

"Nas longas horas de retiro e meditação, na quieta cidade provinciana em que tive o meu berço, foi nas obras dos poetas primaciais desta Casa, - Alvares de Azevedo, Fagundes Varella e Castro Alves, - que eu comecei a amar esta Academia.

"Ela surgia sedutora em minha imaginação, com as graças da sua ancianidade veneranda, envolta nas brumas dos sonhos irrealizaveis.

"Um dia, porém, o que me parecera miragem, no areal da minha peregrinação, se transformou num oasis tranquilo, a cuja sombra depus, por um bocado, o fardo da áspera caminhada. E, numa tarde de dezembro de 1919 , daqui saia armado cavaleiro, para as pugnas do direito.

"Vencidas as primeiras dificuldades da vida prática, uma aspiração mais alta me tomou a mente: quis, ser professor desta $\mathbf{F a -}$ culdade.

"Não cheguei a esta cátedra por um golpe de audácia, que o capricho da sorte houvesse convertido em realidade fagueira. Longas provas de mim exigistes, para que consentisseis, afinal, que eu me assentasse ao vosso lado, nesta Congregação. Sete anos consumi 
na luta sem tréguas por êsse ideal, que tal é o lapso de tempo decorrido entre a minha inscrição ao concurso de Direito Constitucional, na vaga de Herculano de Freitas, em 1926, e a minha atual investidura, como substituto do eminente professor Octavio Mendes, na cadeira de Direito Comercial.

"Trouxe-me aqui o voto de uma comissão de notaveis, que honraria a qualquer Universidade do mundo: Francisco Morato, "maestro di color chi sanno", da estirpe espiritual de João Monteiro, profundo e cristalino, como Lafayette; Syencer Vampré, jurisconsulto dos mais festejados do país e cuja cabeça, precocemente encanecida, revela as demoradas vigílias, a que deve a sua cultura, cada vez mais sólida, cada vez mais extensa; Julio Cesar de Faria, inteligência ciclópica, para quem a ciência do direito já não possue mais segredos; Policarpo de Azevedo, modêlo de magistrado, a quem o Senhor entregaria confiante os seus pleitos, se acaso tivesse algum dia de litigar na terra; Silvio Portugal, uma das organizações mais completas de jurista, de que São Paulo se orgulha e que, trocando a sua béca de advogado pela tóga de juiz, é, em nosso Tribunal de Justiça, uma das sentinelas vigilantes da lei.

"A minha vida, bem o sentis, tem-se desenvolvido, no correr dos anos, nesta Academia e por esta Academia. As modestas obras que publiquei são, todas elas, dissertações para concurso. E até uns pobres versos de minha juventude, reunidos em volume, são versos de meu tempo de estudante, muitos deles nascidos entre estas paredes, quasi tres vezes centenarias.

"Não posso fazer-vos, no dia de hoje, melhor profissão de fé. A obtenção dêste laurel, que não mereço, tomo-o, assim, como dádiva divina, em prêmio ao meu esfôrço e á minha fidelidade a esta Casa querida.

"Bem certo estou de que não poderei honrá-la, acrescendo novas glórias ao acervo precioso de seu passado. Todavia, prometo-vos esforçar-me para não desmerecê-las. Velarei por elas com a maior devoção, cultuando-as com o mais férvido carinho.

"A herança que eu recolho, neste momento, enche-me de enormes responsabilidades. Não é empresa fácil, por certo, o substituir a um professor da estatura de Octavio Mendes.

"Chumbado á terra pela miséria física, o seu espirito sempre pairava nas regiões elevadas do ideal.

"Quando aqui entrou, pela porta de um concurso que fez época na história desta Faculdade, já trazia a fama de grande jurisconsulto; que soube ainda melhor robustecer. Disputava-lhe a cadeira um moço de menos de 35 anos, que já conquistára as esporas de oiro de cavaleiro e deixava entrever o futuro radioso, que lhe sorria; aquele a quem o destino reservava o vir a ser uma das mais empol- 
gantes figuras do movimento cívico, com que São Paulo assombrou o mundo, em julho de 1932, - o professor Waldemar Ferreira.

"As lições que o meu ilustre predecessor, Octavio Mendes, professou nesta Faculdade, correm impressas em dois volumes, compulsados amiudadamente não só por estudantes, como, tambem, por juizes e advogados: "Direito Comercial Terrestre" e "Falencias e concordatas". Além dêsses livros, publicou o emérito catedrático as suas tres dissertações de concurso e uma esplendida monografia, "Dos Títulos de crédito", sem contar algumas dezenas de trabalhos forenses, em que versou as mais diversas e complexas questões agitadas em nosso fôro, nos últimos quarenta anos.

“As responsabilidades, que óra assumo, não me pódem, contudo, apavorar. Bem que os meus ombros são fracos, para suportar peso tão grande. Vejo, porém, entre os membros da douta Congregação, as fisionomias amigas de alguns de meus mestres mais caros de outróra. Nesta sala ainda pairam as sombras amadas de outros, que se foram. Os exemplos daqueles e a evocação dêstes, hão de ser o meu escudo e a minha benção.

“As benévolas palavras de saudação, com que me distinguiu o exmo. sr. Diretor interino, repercutiram no fundo da minha alma. Eu as recebo agradecido, como expressão da generosidade de s. exa. para comigo.

"Senhores.

"Inaugura-se agora uma nova fase na vida desta Faculdade, que vai levar o contingente de sua tradição, alicerçada num século de cultura e de civismo, á nascente Universidade de São Paulo. E' o sonho de Martim Francisco, na Assembléia Constituinte de 1823, corporificado na criação majestosa, com que o patriotismo do sr. Armando de Salles Oliveira, eminente interventor federal neste Estado, coroou a obra da organização do ensino em nossa terra.

"Mas, esta Academia bem amada jamais repoisa sôbre os loiros já colhidos. Cada ano que passa, ela encontra, na obra das gerações que se sucedem, novas fontes de sensação e de enlevo.

"Creio no futuro desta Casa como creio no seu passado. A mocidade, que por aqui passa, estuante de vida e de idealismo, é a mesma mocidade que fez as campanhas da abolição e da república. Porque tendes sabido ensinar-lhe, senhores professores, com os principios do direito e da justiça, a amar a êste torrão bendito, que embala os seus sonhos de grandeza, os olhos voltados para êste velho convento de São Francisco, cujos muros sentem que neles repercutem há cento e sete anos, todas as vibrações da alma nacional." 


\section{OBRAS PUBLICADAS}

Poemas do Deserto, (1914-1919), com o pseudonimo de Euclides Lara. - Casa Mayença. - São Paulo, 1923.

A Intervenção Federal nos Estados - 1. edição, São Paulo-Editora Limitada - São Paulo, 1926; 2." edição, Empresa Grafica da "Revista dos Tribunais" — São Paulo, 1930.

O Artigo 63 da Constituição - São Paulo-Editora Limitada -- São Paulo, 1926.

A Clausula "Cif" - São Paulo-Editora Limitada - São Paulo, 1927. Das Ações Preferenciais nas Sociedades Anonimas - Livraria Academica, Saraiva \& Cia. - São Paulo, 1933. 